\title{
3D PRESSURE TRANSIENT ANALYSIS MODEL OF FRACTURED-CAVED RESERVOIR BASED ON SEISMIC CHARACTERIZATION
}

\author{
Yizhao Wan, ${ }^{1,2, *}$ Nengyou $\mathrm{Wu}^{1,2}$ Changling Liu, ${ }^{1,2}$ Qiang Chen, ${ }^{1,2} \mathcal{E}$ \\ Yuewu Liu $^{3}$
}

${ }^{1}$ The Key Laboratory of Gas Hydrate, Ministry of Natural Resources of the People's Republic of China, Qingdao Institute of Marine Geology, Qingdao, 266071, China

${ }^{2}$ Laboratory for Marine Mineral Resources, Qingdao Pilot National Laboratory for Marine Science and Technology, Qingdao, 266071, China

${ }^{3}$ Institute of Mechanics, Chinese Academy of Sciences, Beijing, 100190, China

*Address all correspondence to: Yizhao Wan, The Key Laboratory of Gas Hydrate, Ministry of Natural Resources of the People's Republic of China, Qingdao Institute of Marine Geology, Qingdao, 266071, China, E-mail: wanyizhao@mail.cgs.gov.cn

Original Manuscript Submitted: 9/18/2017; Final Draft Received: 8/17/2018

\begin{abstract}
Large-scale fractures and cavities cause difficulties of geological modeling, which in turn makes the fluid flow simulation difficult. In this paper, a geological modeling process based on three-dimensional (3D) seismic characterization is proposed to model real reservoirs, and then a 3D pressure transient analysis model is developed to model the fluid flow in the fractured-caved reservoirs. In this model, the reservoir is characterized as three types of media explicitly: cavities simplified as irregular polyhedrons, fractures represented by slabs, and the matrix of the rest. A finite-element method is implemented to obtain the solutions of the governing equations. Two idealized cases of fractures and cavities are presented using the model. The results show fractures and cavities play the dominant role in the fluid flow. In the fractures case, the log-log type curves can be divided into six stages, and the bilinear flow is the main feature. A larger permeability of fractures causes a longer period of bilinear flow. The log-log type curves of the cavity case are also divided into six stages. The larger permeability of cavities, the lower the horizontal line of the pressure derivative, but the influence of cavities not connected with the wellbore is limited. Comparison with the radial-composite model shows that the radial-composite model gets a volume-equivalent radius of the cavity, but a higher permeability and a negative skin factor. The developed model is also applied for the well test analysis of a field case, which shows a significant ability to characterize the fluid flow of fractured-caved reservoirs.
\end{abstract}

KEY WORDS: fractured-caved reservoirs, 3D seismic characterization, finite-element method, pressure analysis, numerical well testing

\section{INTRODUCTION}

Carbonate reservoirs make a big contribution to fossil energy. The significant characteristics of the fractured-caved reservoirs are the development of large-scale fractures and cavities, and their random distribution causes drilling breakage and leakage of mud during the drilling process (Li et al., 2016), so the fractured-caved reservoirs are very different from sandstone reservoirs and naturally fractured reservoirs. For the reservoir development, it is very important to know what the role of the large-scale fractures and cavities play in the oil or gas recovery. However, it is a big challenge to characterize this kind of reservoir and to model the fluid flow in these complex porous media because of the special characteristics. One can refer to the literature (Ran et al., 2014; Zhu et al., 2015) to get more information about the characteristics of the fractured-caved reservoirs. 


\begin{tabular}{|llll|}
\hline & & & \\
& & & \\
& & & \\
$K_{m}$ & permeability of matrix $\left(\mathrm{m}^{2}\right)$ & $C$ & wellbore storage coefficient $\left(\mathrm{m}^{3} / \mathrm{Pa}\right)$ \\
$K_{v}$ & permeability of cavity $\left(\mathrm{m}^{2}\right)$ & $M$ & mobility ratio of cavity and matrix \\
$K_{f}$ & permeability of fracture $\left(\mathrm{m}^{2}\right)$ & $V_{v 1}$ & volume of the cavity $\left(\mathrm{m}^{3}\right)$ \\
$\mu$ & viscosity of the fluid $(\mathrm{Pa} \cdot \mathrm{s})$ & $x_{i}^{m}, y_{i}^{m}, z_{i}^{m}$ & coordinates of the matrix's node $i(\mathrm{~m})$ \\
$P_{m}$ & pore pressure of matrix $(\mathrm{Pa})$ & $x_{i}^{\prime}, y_{i}^{\prime}$ & local coordinates of the fractures' node $i(\mathrm{~m})$ \\
$P_{v}$ & pore pressure of cavity $(\mathrm{Pa})$ & $\Gamma_{i}$ & wellbore boundary \\
$P_{f}$ & pore pressure of fracture $(\mathrm{Pa})$ & $\Gamma_{o}$ & reservoir boundary \\
$p_{i}$ & initial pressure of reservoirs $(\mathrm{Pa})$ & $\Gamma_{v}$ & interface of matrix and cavity \\
$p_{w}$ & bottom hole pressure $(\mathrm{Pa})$ & $n_{i}$ & external normal line of wellbore surface \\
$\phi_{m}$ & porosity of matrix & $n_{o}$ & external normal line of reservoir boundary \\
$\phi_{v}$ & porosity of cavity & $n_{v}$ & external normal line of the interface \\
$\phi_{f}$ & porosity of fracture & $\Omega_{m}$ & region of matrix \\
$C_{t}$ & total compressibility $\left(\mathrm{Pa} \mathrm{a}^{-1}\right)$ & $\Omega_{v}$ & region of cavity \\
$A$ & area of wellbore surface $\left(\mathrm{m}^{2}\right)$ & $\Omega_{f}$ & region of fracture \\
$B$ & volume factor $\left(\mathrm{m}^{3} / \mathrm{m}^{3}\right)$ & $\Omega_{f}$ & simplified two-dimensional fracture region \\
& & & \\
\hline
\end{tabular}

At present, there are three kinds of models for the modeling of fluid flow in carbonate reservoirs: the continuum media model (CMM), the equivalent continuum media model (ECM), and the discrete medium model (DMM). Typical representatives of CMM are the multiple media models (MMMs), such as the dual porosity model, dual permeability model, and dual permeability model. The dual porosity model, consisting of the fracture system and matrix system for naturally fractured reservoirs, was first proposed by Barenblatt et al. (1960). The flow in the matrix and fractures is described with Darcy's law, and the flow between matrix system and fracture system is represented by an interporosity transfer function. Then, Warren and Root (1963) extended it to orthotropic media and developed a so-called Warren-Root model. Inspired by the Warren-Root model, many authors did a lot of studies on the aforementioned dual media, for example, the transient interporosity flow model of lamellar (Kazemi, 1969) and spherical (de Swaan, 1976) shape matrixes. Some experimental and numerical studies focused on the interporosity flow are also reported, and more precisely an empirical model of the interporosity flow is proposed (Zendehboudi et al., 2009, 2011; Wan et al., 2016). Clossman (1975) proposed a triple media model that divided the matrix system of dual media model to two kinds of media and added more transfer functions between the different kinds of media. The third media would be vug or matrix with different properties. After that, the multiple media model has been extended to the fluid flow description of different wells' types (Fuentes-Cruz and Valko, 2015), different flow mechanics (Kolditz, 2002), and different formation traits (Zendehboudi et al., 2014).

MMMs are commonly used in the fractured-caved reservoirs (Khvatova et al., 2012; Shakerinezhad et al., 2013). In the model, each medium is continuous and overlapped with each other, which implies that a spatial point possesses the triple media simultaneously. If we take a representative elementary volume (REV) of the fractured-caved media, fractures, matrix, and cavities will fill up the REV, respectively. However, for the fractured-caved reservoirs, the size of the cavity is as large as several meters or more, and the cavities are isolated. It is not possible to fill up the REV with fractures, matrix, and cavities simultaneously, so it is not appropriate to model fluid flow in the fracture-caved reservoir by MMMs (Wan et al., 2018).

In ECM, a research area with fractures, matrix, and cavities is divided into grids, and a permeability tensor of all grids is calculated. Then, all of the grids are combined as a new equivalent continuum media represented by an anisotropic permeability tensor (Snow, 1969). The core concept of ECM is to demonstrate the heterogeneity by the anisotropy under a proper REV. ECM can use the classical continuum media theory, which is the advantage. There are also some disadvantages of ECM: (1) the problem of validity, i.e., not all the media can be equivalent to ECM (Long et al., 1982; Dayani et al., 2012); (2) it is difficult to determine the size of REVs (Zhang and Xu, 2008); and (3) the 
local flow detail is omitted and the significant effect of fractures and cavities on the fluid flow cannot be demonstrated clearly.

DMM is mainly applied in naturally fractured reservoirs and is called the discrete-fracture model (DFM). Recently, Huang et al. $(2010,2014)$ proposed a discrete fractured-vuggy model which considers the vugs in reservoirs. The concept of DMM is to describe the fractures and cavities explicitly and to model the fluid flow in fractures and cavities (Grillo et al., 2012). DMM captures the details of fluid flow (Kim and Deo, 1999; Yao et al., 2013) and describes the flow pattern in complex media, and it is the most precise method to model the fluid flow in fractured-caved reservoirs. However, disadvantages of DMM are also evident. DMM is highly dependent on the topological information about fractures and cavities, which is difficult to get (Yu et al., 2014). On the other hand, the large amount of fractures and cavities leads to a time-consuming computation (Jambayev and Hoffman, 2015).

Another very commonly used model for fluid flow description in fractured-caved reservoirs is the radial-composite model, which is proposed for studying the pressure behavior in a composite reservoir with two adjacent concentric zones of different permeability (Loucks and Guerrero, 1961; Yao et al., 2016). Reservoir engineers prefer the radialcomposite model for two reasons (Xing et al., 2018). First, if the well is drilled in a large-scale cavity, the cavity can be seen as the inner zone with high permeability. The second and more important reason is that the tested pressure curves of the fractured-caved reservoirs in some wells show a similar type of the radial-composite model. However, the inner zone of the radial-composite model runs through the reservoir in the vertical direction, and it is a cylinder with a well in the center. These are inconsistent with the real situation of the fractured-caved reservoirs. More importantly, the radial-composite model cannot include fractures.

In summary, the current models for the fluid flow in the fractured-caved reservoirs are not appropriate. In this paper, a model for the fluid flow modeling of fractured-caved reservoirs is proposed. The geological model is developed based on the three-dimensional (3D) seismic characterization. Fractures are simplified as plates in two dimensions using DFM, and cavities are represented by irregular polyhedrons with large permeability and high porosity. The mathematical model with governing equations for matrix, fractures, and cavities are established based on Darcy's law. A finite-element method is implemented to solve the mathematical models with triangular meshes for the faces of fractures and tetrahedron meshes for cavities and matrix. Two idealized cases with only fractures and only cavities are proposed, and sensitivity studies are performed to illustrate the role the fractures and cavities play in the fluid flow of fractured-caved reservoirs. The developed model is also applied in well test analysis of a field case, which shows a significant ability to characterize the fluid flow of fractured-caved reservoirs.

\section{GEOLOGICAL MODEL DEVELOPMENT BASED ON THE SEISMIC CHARACTERIZATION}

As mentioned previously, the main disadvantage of DMM is the difficulty of geological modeling, and the main challenge for geological modeling is the determination of fractures and cavities. In this section, we propose a method to establish the geological model of fractured-caved reservoirs. Seismic geometric attributes are extracted from utilizing seismic data to describe geological properties such as karst watercourse, karst cavity, plane round or elliptic fracture features, and fracture channel related karst reservoirs. The seismic facies analysis could be used to confirm the spatial distribution of major karst features like karst cavity and fracture channel and the threshold value of seismic geometric attributes. Spatial connectivity of major karst features is analyzed to build the spatial structural model of fracturedcaved connectors (Zheng et al., 2011). Using the results of seismic characterization, we develop the geological models for numerical simulation. The process is presented in Fig. 1:

1. Seismic geometric attributes such as dips, amplitude gradients, and curvatures are extracted.

2. Beads like reflection, fractures reflection, and disorder reflection are obtained by seismic facies analysis based on a Bayesian probability model.

3. Then, all the structures are combined as a whole volume named fractured-caved structures.

4. In the fractured-caved structures, effective-connected structures are retained.

Volume 22, Issue 11, 2019 

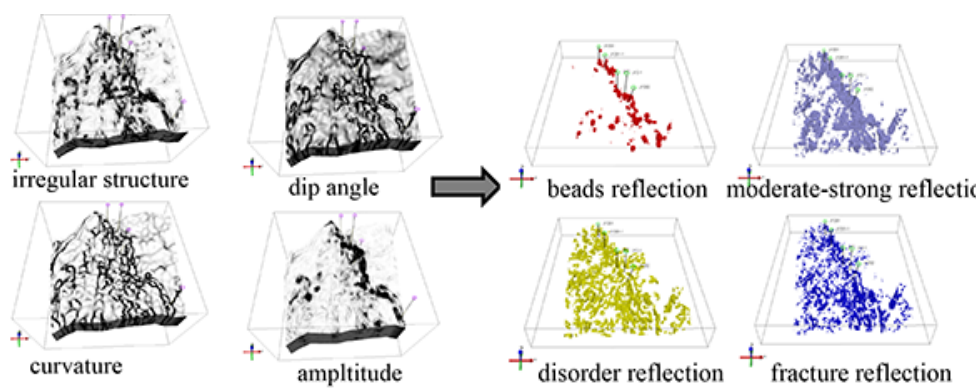

(a) extraction of seismic geometric attributes

(b) seismic facies analysis

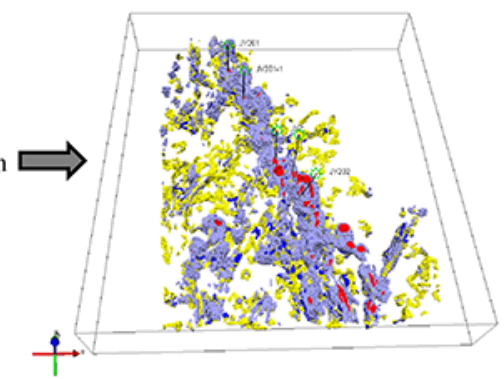

(c) fractured-caved structures

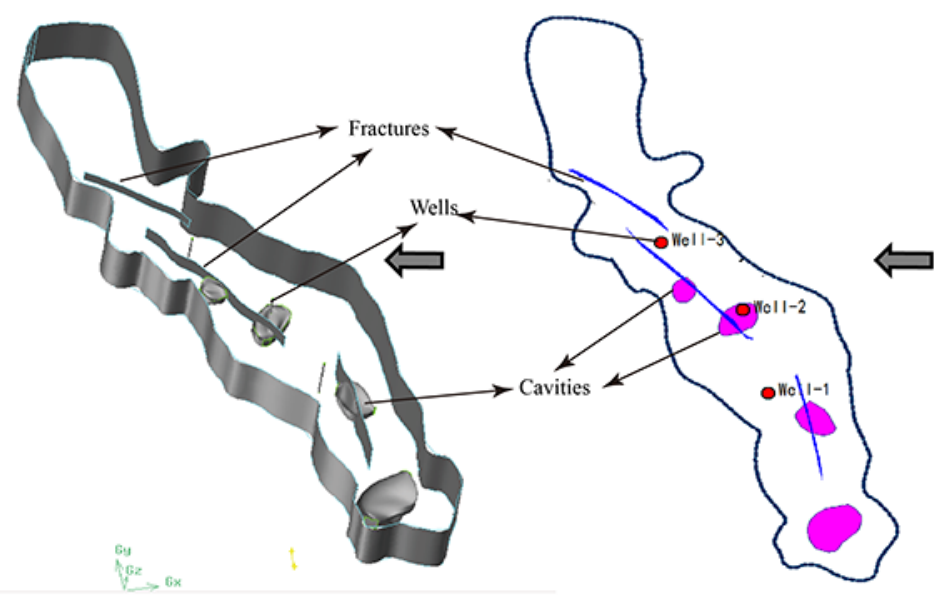

(f) geological model

(e) fractured-caved unit

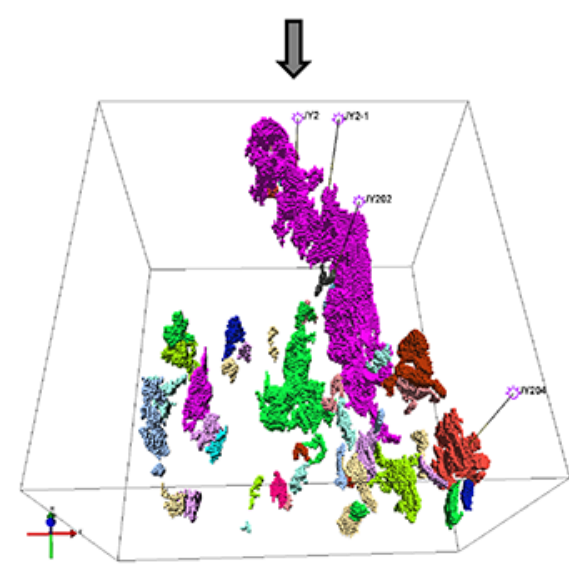

(d) effective connected structures

FIG. 1: Process of geological modeling: (a) extraction of seismic geometric attributes; (b) seismic facies analysis; (c) fracturedcaved structures; (d) effective connected structures; (e) fractured-caved unit; and (f) geological model

5. In the effective-connected structures, the fractures and cavities extracted from the fractures and beads like reflection are drawn. Then a fractured-caved unit is given.

6. A geological model based on the fractured-caved unit is developed.

The large-scale fractures and cavities in Step 5 [Fig. 1(e)] are only the ones that can be interpreted by the seismic data. In fact, many other fractures and cavities cannot be recognized because of the low accuracy of seismic data. All these unrecognizable fractures and cavities appear as a part of the matrix (Teimoori, 2005). Then, the geological model of the fracture-caved unit is developed in Step 6 [Fig. 1(f)]. This method will ignore many details of the reservoirs, but it captures the main features of the reservoir that dominate the fluid flow.

\section{MATHEMATICAL MODEL AND NUMERICAL SOLUTION}

\subsection{Mathematical Model}

In the geological model, the entire reservoir is divided into three regions: the matrix including the unrecognizable fractures and cavities, the large-scale fractures, and the large-scale cavities. It should be noted that there are two kinds of cavities, filled cavities and unfilled cavities (Wan et al., 2018). In this paper, we just consider the filled cavities, which means that Darcy's law can be applied in the fluid flow description.

First, we make some assumptions for the development of the mathematical model: (1) The reservoir formation with a uniform thickness is horizontal. The top and bottom boundaries are impermeable. (2) Only the cavities filled 
up with argillaceous rocks and breccia are taken into account. The flow in the fractures and cavities obey Darcy's law. (3) Fluid in the pore space is assumed to be weakly compressible, and the compressibility is constant. (4) The wellbore storage is considered, but gravity and capillary effect are ignored.

\subsubsection{Governing Equation for Fluid Flow in Matrix Region}

In the matrix region, governing equation for fluid flow is given by Wan et al. (2018):

$$
\frac{\partial^{2} p_{m}}{\partial x^{2}}+\frac{\partial^{2} p_{m}}{\partial y^{2}}+\frac{\partial^{2} p_{m}}{\partial z^{2}}=\frac{\phi_{m} \mu C_{t}}{K_{m}} \frac{\partial p_{m}}{\partial t}
$$

\subsubsection{Governing Equation for Fluid Flow in Cavities}

We assume the fluid flow in the filled cavities still obeys Darcy's law. Then, the governing equation for cavities holds the same form as that for matrix, which is given by:

$$
\frac{\partial^{2} p_{v}}{\partial x^{2}}+\frac{\partial^{2} p_{v}}{\partial y^{2}}+\frac{\partial^{2} p_{v}}{\partial z^{2}}=\frac{\phi_{v} \mu C_{t}}{K_{v}} \frac{\partial p_{v}}{\partial t}
$$

\subsubsection{Governing Equation for Fluid Flow in Fractures}

Using DFM, the flow in the direction perpendicular to the fracture surface is ignored. The 3D fracture turns into two-dimensional (2D). Then, the governing equation for fractures is a 2D one, which is given by Wan et al. (2015):

$$
\frac{\partial^{2} p_{f}}{\partial x^{\prime 2}}+\frac{\partial^{2} p_{f}}{\partial y^{\prime 2}}=\frac{\mu \phi_{f} C_{t}}{K_{f}} \frac{\partial p_{f}}{\partial t}
$$

It should be noted that $x^{\prime}$ and $y^{\prime}$ are the local coordinates of fractures.

\subsubsection{Initial Conditions and Boundary Conditions}

The initial condition of the reservoirs is that the formation pressure is the initial pressure.

$$
p_{m}(t=0)=p_{i}, \quad p_{v}(t=0)=p_{i}, \quad p_{f}(t=0)=p_{i}
$$

The surface flow rate of the well is equal to the sum of the sand face rate and the volume change of fluid stored in the wellbore. Then, the wellbore boundary condition is:

$$
\begin{aligned}
\left.A \frac{K}{\mu} \frac{\partial p}{\partial n_{i}}\right|_{\Gamma_{i}}=B q+C \frac{d p_{w}}{d t} \\
\left.p\right|_{\Gamma_{i}}=p_{w}
\end{aligned}
$$

There are two types of reservoir boundary condition:

constant pressure boundary,

$$
\left.p\right|_{\Gamma_{o}}=p_{i}
$$

no-flow boundary,

$$
\left.\frac{\partial p}{\partial n_{o}}\right|_{\Gamma_{o}}=0
$$

Another important condition is the interface condition between matrix and cavity. It is quite natural that the pressure and flow rate in the interface are continuous, which implies that the interface condition is:

$$
\left.p_{m}\right|_{\Gamma_{v}}=\left.p_{v}\right|_{\Gamma_{v}}
$$

Volume 22, Issue 11, 2019 


$$
\left.\frac{\partial p_{m}}{\partial n_{v}}\right|_{\Gamma_{v}}=\left.M \frac{\partial p_{v}}{\partial n_{v}}\right|_{\Gamma_{v}}
$$

If $F E Q$ represents governing equations of the whole target region, the integral form of the equations can be given by:

$$
\iiint_{\Omega} F E Q d \Omega=\iiint_{\Omega_{m}} F E Q d \Omega_{m}+\iiint_{\Omega_{v}} F E Q d \Omega_{v}+\iiint_{\Omega_{f}} F E Q d \Omega_{f}
$$

It should be noticed that the governing Eq. (3) of fractures is in two dimensions. When one applies the DFM in fractures, Eq. (11) can be written as follows (Wan et al., 2015):

$$
\iiint_{\Omega} F E Q d \Omega=\iiint_{\Omega_{m}} F E Q d \Omega_{m}+\iiint_{\Omega_{v}} F E Q d \Omega_{v}+w \cdot \iint_{\overline{\Omega_{f}}} F E Q d \overline{\Omega_{f}}
$$

where $w$ is the thickness of the fractures.

We use Eq. (12) to connect the governing equations of fractures and matrix.

\subsection{Numerical Solutions of the Mathematical Model}

Using a Galerkin weighted residual technique on elements (Galerkin, 1915; Wan et al., 2018), the form of weak integration of governing equations for matrix, cavity, and fracture can be presented as follows:

$$
\begin{gathered}
\iiint_{V_{m}}\left(\frac{\partial p_{m}}{\partial x} \frac{\partial \delta p_{m}}{\partial x}+\frac{\partial p_{m}}{\partial y} \frac{\partial \delta p_{m}}{\partial y}+\frac{\partial p_{m}}{\partial z} \frac{\partial \delta p_{m}}{\partial z}+\frac{\phi_{m} \mu C_{t}}{K_{m}} \frac{\partial p_{m}}{\partial t} \delta p_{m}\right) d V_{m}=\iint_{A_{m}} \delta p_{m} \frac{\partial p_{m}}{\partial n} d A_{m} \\
\iiint_{V_{v}}\left(\frac{\partial p_{v}}{\partial x} \frac{\partial \delta p_{v}}{\partial x}+\frac{\partial p_{v}}{\partial y} \frac{\partial \delta p_{v}}{\partial y}+\frac{\partial p_{v}}{\partial z} \frac{\partial \delta p_{v}}{\partial z}+\frac{\phi_{v} \mu C_{t}}{K_{v}} \frac{\partial p_{v}}{\partial t} \delta p_{v}\right) d V_{v}=\iint_{A_{v}} \delta p_{v} \frac{\partial p_{v}}{\partial n} d A_{v} \\
\iint_{A^{\prime}}\left(\frac{\partial p_{f}}{\partial x^{\prime}} \frac{\partial \delta p_{f}}{\partial x}+\frac{\partial p_{f}}{\partial y^{\prime}} \frac{\partial \delta p_{f}}{\partial y^{\prime}}+\frac{\phi_{f} \mu C_{t}}{K_{f}} \frac{\partial p_{f}}{\partial t} \delta p_{f}\right) d A^{\prime}=\int_{S} \delta p_{f} \frac{\partial p_{f}}{\partial n} d s
\end{gathered}
$$

It should be noted that the right terms of Eq. (13) through Eq. (15) are the flow rate of the element borders. When one assembles all the element equations into whole finite-element equations, these right terms will be counteracted with each other except for the ones on the wellbore boundary under the following condition:

$$
\iint_{A_{m}} \frac{\partial p_{m}}{\partial n} d A_{m}+M \iint_{A_{v}} \frac{\partial p_{v}}{\partial n} d A_{v}=0
$$

The matrix pressure on the element is

$$
p_{m}=p_{m i} N_{m i}+p_{m j} N_{m j}+p_{m k} N_{m k}+p_{m l} N_{m l}
$$

where $N_{m i}=a_{m i}+b_{m i} x+c_{m i} y+d_{m i} z ; i, j, k, l=1,2,3,4$.

The cavity pressure in the element is

$$
p_{v}=p_{v i} N_{v i}+p_{v j} N_{v j}+p_{v k} N_{v k}+p_{v l} N_{v l}
$$

where $N_{v i}=a_{v i}+b_{v i} x+c_{v i} y+d_{v i} z ; i, j, k, l=1,2,3,4$.

The fracture pressure in the element is

$$
p_{f}=p_{f i} N_{f i}+p_{f j} N_{f j}+p_{f k} N_{f k}
$$

where $N_{f i}=a_{f i}+b_{f i} x^{\prime}+c_{f i} y^{\prime} ; i, j, k=1,2,3$. 
Substituting Eqs. (17), (18), and (19) into Eqs. (13), (14), and (15) respectively, we can get the element equation for the matrix, the cavity, and the fracture.

The element equation for the matrix is:

$$
\begin{aligned}
& V_{m}\left(b_{m i}^{2}+c_{m i}^{2}+\frac{K_{m z}}{K_{m}} d_{m i}^{2}+\frac{\phi_{m} \mu c_{t}}{K_{m}} \frac{1}{10 \Delta t}\right) p_{m i}^{n+1} \\
& +V_{m}\left(b_{m i} b_{m j}+c_{m i} c_{m j}+\frac{K_{m z}}{K_{m}} d_{m i} d_{m j}+\frac{\phi_{m} \mu c_{t}}{K_{m}} \frac{1}{20 \Delta t}\right) p_{m j}^{n+1} \\
& +V_{m}\left(b_{m i} b_{m k}+c_{m i} c_{m k}+\frac{K_{m z}}{K_{m}} d_{m i} d_{m k}+\frac{\phi_{m} \mu c_{t}}{K_{m}} \frac{1}{20 \Delta t}\right) p_{m k}^{n+1} \\
& +V_{m}\left(b_{m i} b_{m l}+c_{m i} c_{m l}+\frac{K_{m z}}{K_{m}} d_{m i} d_{m l}+\frac{\phi_{m} \mu c_{t}}{K_{m}} \frac{1}{20 \Delta t}\right) p_{m l}^{n+1} \\
& -\frac{A_{m}}{6} \frac{\partial p_{m i}^{n+1}}{\partial n}-\frac{A_{m}}{12} \frac{\partial p_{m j, m k, m l}^{n+1}}{\partial n}-\frac{A_{m}}{12} \frac{\partial p_{m k, m l, m j}^{n+1}}{\partial n} \\
& =\frac{\phi_{m} \mu c_{t}}{K_{m}} \frac{V_{m}}{10 \Delta t} p_{m i}^{n}+\frac{\phi_{m} \mu c_{t}}{K_{m}} \frac{V_{m}}{20 \Delta t} p_{m j}^{n}+\frac{\phi_{m} \mu c_{t}}{K_{m}} \frac{V}{20 \Delta t} p_{m k}^{n}+\frac{\phi_{m} \mu c_{t}}{K_{m}} \frac{V}{20 \Delta t} p_{m l}^{n}
\end{aligned}
$$

where $V_{m}=\frac{1}{6}\left|\begin{array}{cccc}1 & x_{i}^{m} & y_{i}^{m} & z_{i}^{m} \\ 1 & x_{j}^{m} & y_{j}^{m} & z_{j}^{m} \\ 1 & x_{k}^{m} & y_{k}^{m} & z_{k}^{m} \\ 1 & x_{l}^{m} & y_{l}^{m} & z_{l}^{m}\end{array}\right|, b_{m i}=-\frac{1}{6 V_{m}}\left|\begin{array}{ccc}1 & y_{j}^{m} & z_{j}^{m} \\ 1 & y_{k}^{m} & z_{k}^{m} \\ 1 & y_{l}^{m} & z_{l}^{m}\end{array}\right|, c_{m i}=\frac{1}{6 V_{m}}\left|\begin{array}{ccc}1 & x_{j}^{m} & z_{j}^{m} \\ 1 & x_{k}^{m} & z_{k}^{m} \\ 1 & x_{l}^{m} & z_{l}^{m}\end{array}\right|$, and $d_{\mathrm{m} i}=-\frac{1}{6 V_{m}}\left|\begin{array}{lll}1 & x_{j}^{m} & y_{j}^{m} \\ 1 & x_{k}^{m} & y_{k}^{m} \\ 1 & x_{l}^{m} & y_{l}^{m}\end{array}\right|$

The element equation for the cavity is as the same form of the matrix.

The element equation for the fracture is

$$
\begin{aligned}
& A\left(b_{f i} b_{f i}+c_{f i} c_{f i}+\frac{\phi_{f} \mu c_{t}}{K_{f}} \frac{1}{6 \Delta t}\right) p_{f i}^{n+1}+A\left(b_{f i} b_{f j}+c_{f i} c_{f j}+\frac{\phi_{f} \mu c_{t}}{K_{f}} \frac{1}{12 \Delta t}\right) p_{f j}^{n+1} \\
& +A\left(b_{f i} b_{f k}+c_{f i} c_{f k}+\frac{\phi_{f} \mu c_{t}}{K_{f}} \frac{1}{12 \Delta t}\right) p_{f k}^{n+1} \\
& =\frac{\phi_{f} \mu c_{t}}{K_{f}} \frac{1}{6 \Delta t} p_{f i}^{n}+\frac{\phi_{f} \mu c_{t}}{K_{f}} \frac{1}{12 \Delta t} p_{f j}^{n}+\frac{\phi_{f} \mu c_{t}}{K_{f}} \frac{1}{12 \Delta t} p_{f k}^{n}
\end{aligned}
$$

where $A=\frac{1}{2}\left|\begin{array}{ccc}1 & x_{i}^{\prime} & y_{i}^{\prime} \\ 1 & x_{j}^{\prime} & y_{j}^{\prime} \\ 1 & x_{k}^{\prime} & y_{k}^{\prime}\end{array}\right|, b_{f i}=-\frac{1}{2 A}\left|\begin{array}{cc}1 & y_{j}^{\prime} \\ 1 & y_{k}^{\prime}\end{array}\right|, c_{f i}=\frac{1}{2 A}\left|\begin{array}{cc}1 & x_{j}^{\prime} \\ 1 & x_{k}^{\prime}\end{array}\right|$.

Then, all the element equations can be assembled to get the whole linear system equations (Wan et al., 2015). The solution is obtained by solving the whole linear system equations.

\section{RESULTS AND DISCUSSION}

\subsection{Validation of the Model}

To validate the model developed in this paper, we compare the solutions of this paper with the analytical solutions of the radial-composite model shown in Fig. 2. Figure 3 shows the log-log plots of the analytical solutions of the radial-composite model and the numerical solutions of the model developed in this paper. As can be seen, numerical results are in excellent agreement with the analytical solutions, which means the numerical model developed in this paper is effective. 


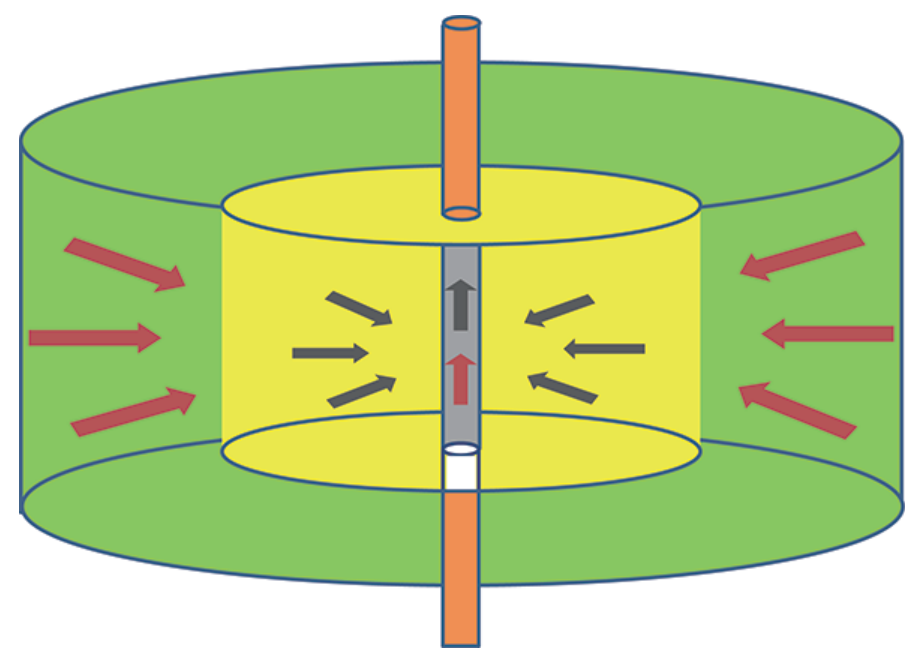

FIG. 2: Schematic diagram of the radial-composite model

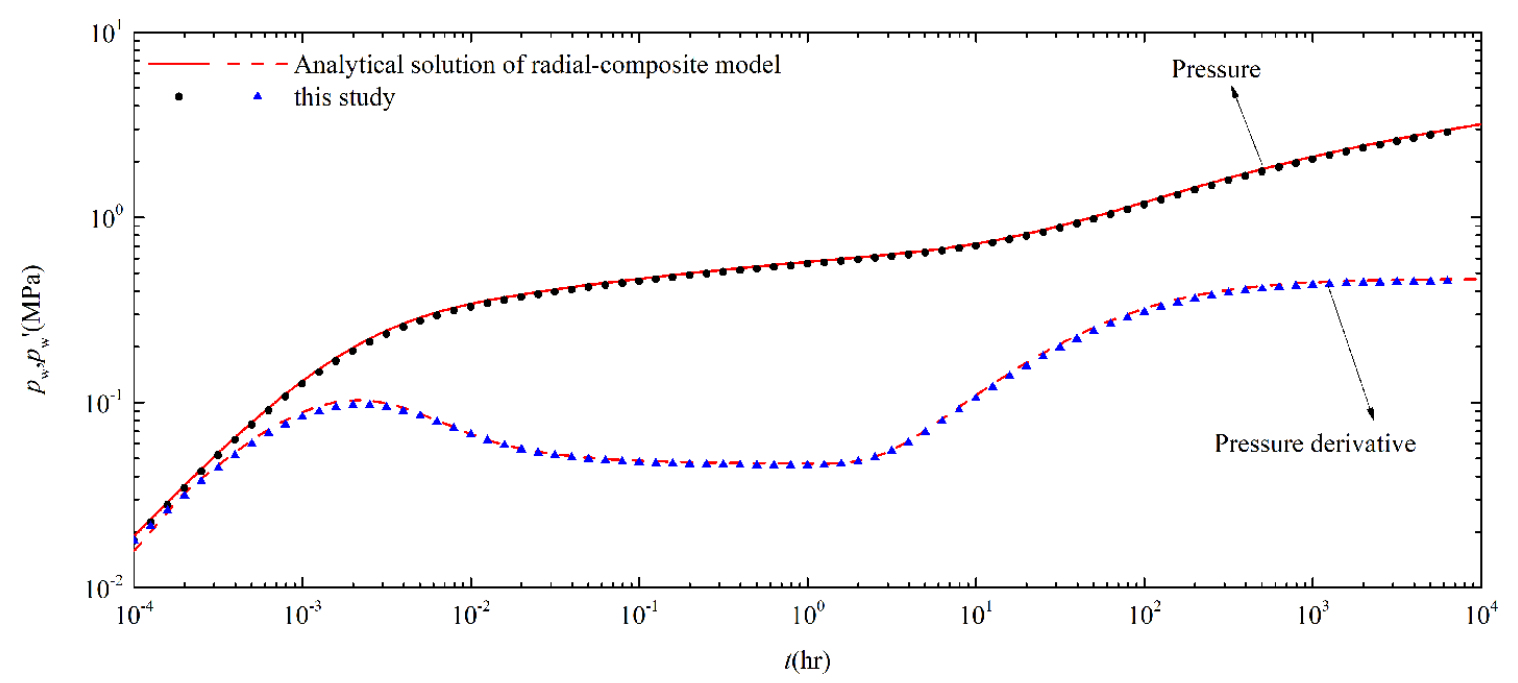

FIG. 3: Log-log plot of bottom hole pressure of radial-composite model

\subsection{The Case of Fractures}

Figure 4 shows a reservoir of $1,000 \times 1,000 \times 300 \mathrm{~m}$ with three fractures intersected with each other, and two of them are intersected with the well, which is located in the center of the reservoir. The fractures are all rectangles, and the thickness is $0.1 \mathrm{~cm}$. The coordinates of the four points of the rectangles for fractures are listed in Table 1 . The permeability of fractures is $10^{6} \mathrm{mD}$, and that of the matrix is $1 \mathrm{mD}$.

\subsubsection{Pressure Transient Analysis}

Figure 5 shows the bottom hole pressure and pressure derivative changing with time in the log-log coordinates. As can be seen, the type curves can be divided into six stages:

1. Wellbore storage period: The flow is dominated by the wellbore storage effect, and the pressure and pressure derivative are a unit-slop line in the log-log plot. 


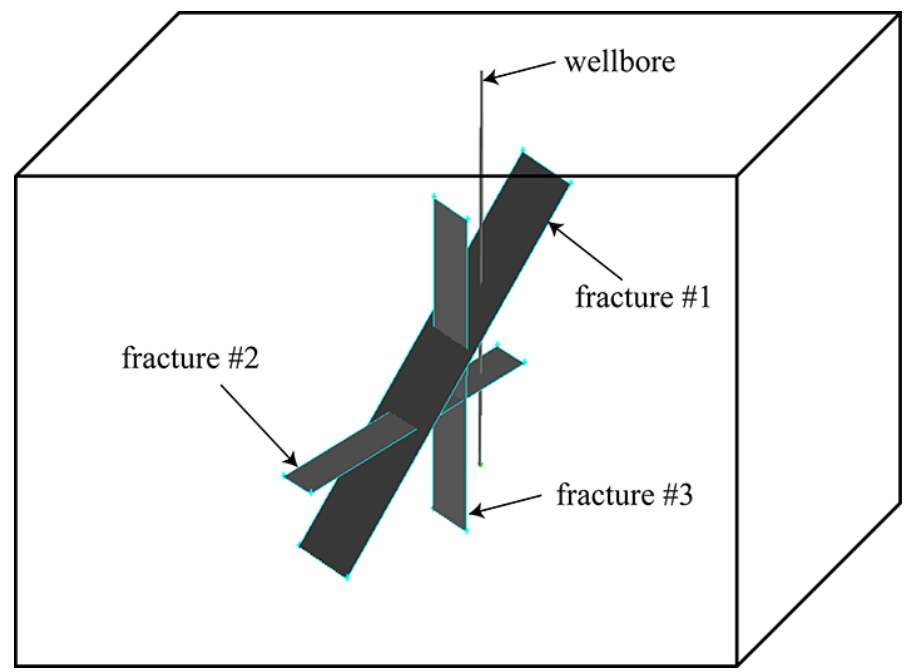

FIG. 4: Geological model of fractures case

TABLE 1: Coordinates of the fractures

\begin{tabular}{|c|c|c|c|c|}
\hline Fracture no. & Point 1 & Point 2 & Point 3 & Point 4 \\
\hline 1 & $(-72,102,-124)$ & $(-72,-42,124)$ & $(72,-42,124)$ & $(72,102,-124)$ \\
\hline 2 & $(-40,119,-74)$ & $(-40,-19,5)$ & $(40,-19,5)$ & $(40,119,-74)$ \\
\hline 3 & $(-50,20,100)$ & $(-50,20,-100)$ & $(50,20,-100)$ & $(50,20,100)$ \\
\hline
\end{tabular}

Coordinate origin is the center of the reservoir

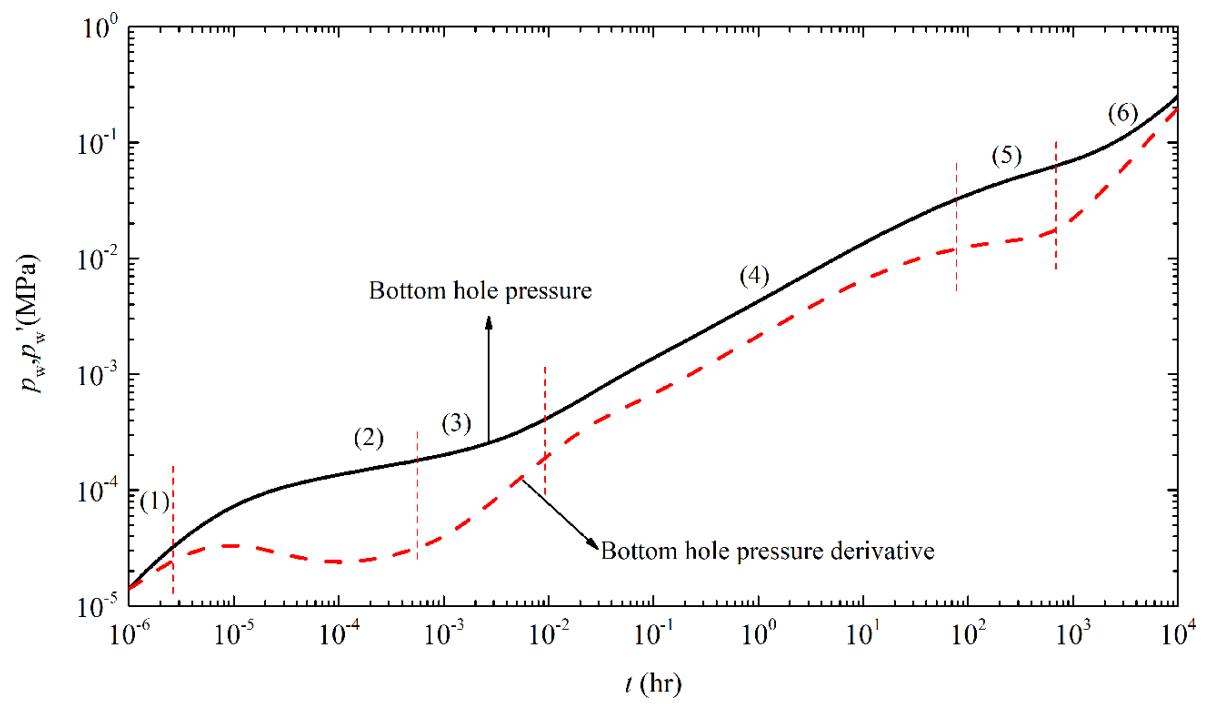

FIG. 5: Log-log plot of bottom hole pressure

2. Radial flow period of the fractures: After the wellbore storage, the fluid flows from the fractures intersected with the wellbore to the well as a radial form because of the high permeability. The pressure derivative is a horizontal line. Figure 6(a) shows the pressure profile in the fractures connected with the wellbore. As can be seen, the pressure contours are concentric circles which means a radial flow. 

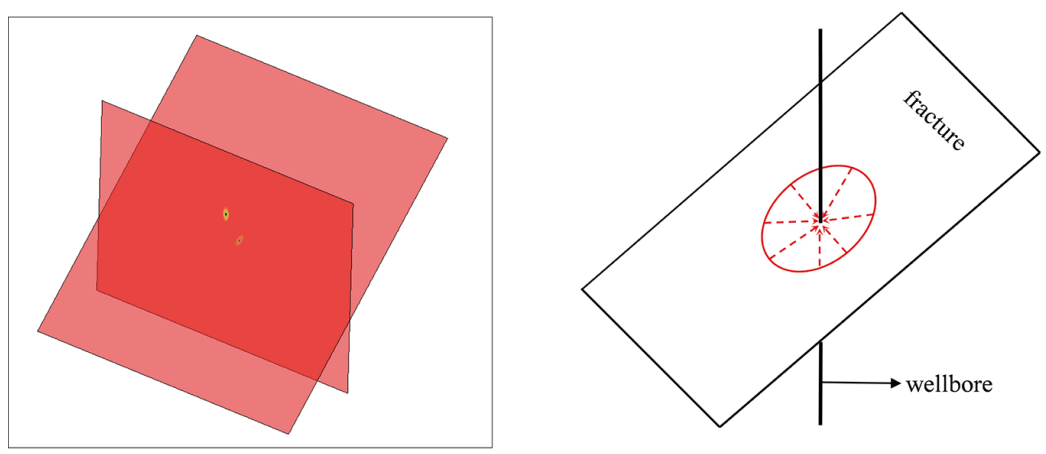

(a) Radial flow of the fractures $\left(t=10^{-4} \mathrm{hr}\right)$
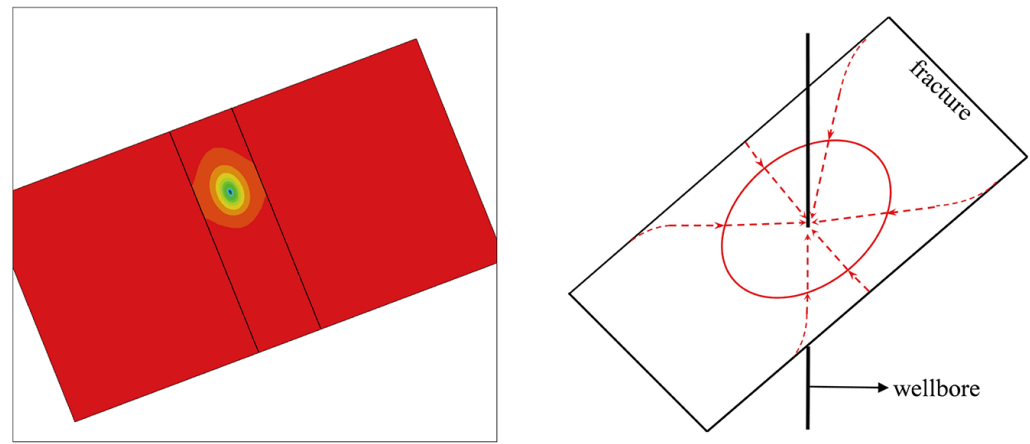

(b) Transient flow $(t=0.005 \mathrm{hr})$
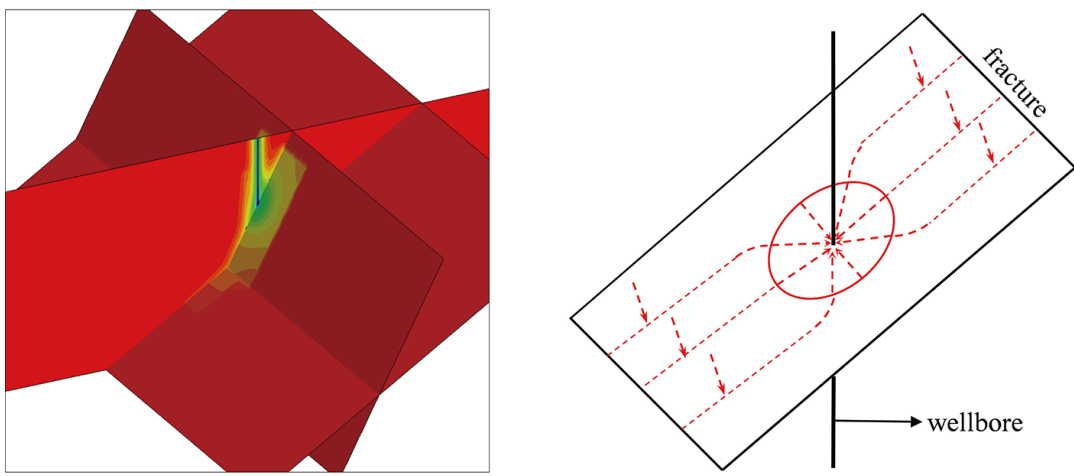

(c) Bilinear flow of the fractures $(t=1 \mathrm{hr})$
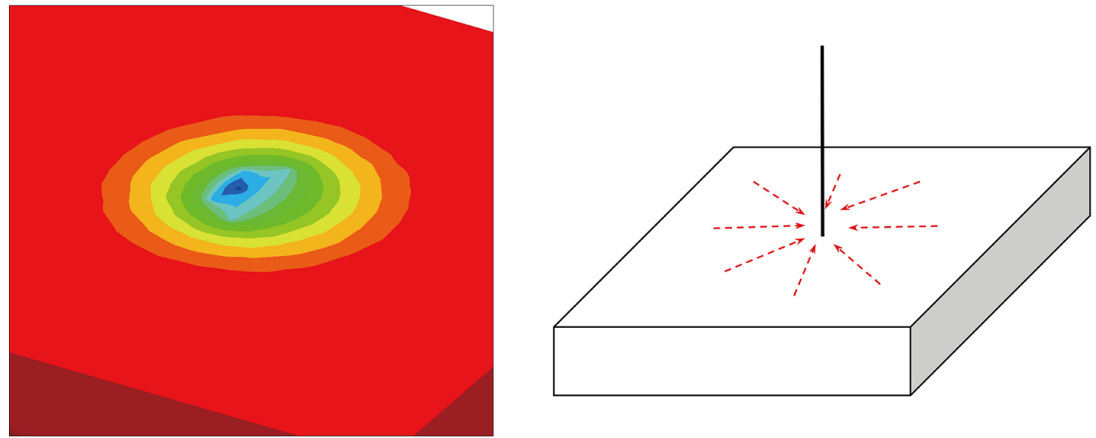

(d) Radial flow of the system ( $t=500 \mathrm{hr})$

FIG. 6: Pressure profile and flow pattern of the model: (a) radial flow of the fractures $\left(t=10^{-4} \mathrm{~h}\right)$; (b) transient flow ( $t=$ $0.005 \mathrm{~h})$; (c) bilinear flow of the fractures $(t=1 \mathrm{~h})$; and $(\mathrm{d})$ radial flow of the system $(t=500 \mathrm{~h})$ 
3. Transient flow period: As the pressure expands in the fractures, the boundaries of the fractures affect the fluid flow. The flow pattern changes gradually from radial flow to linear flow, which is shown in Fig. 6(b).

4. Bilinear flow period: During this period, the fluid flows from the fracture channel to the wellbore as a linear pattern and fluid flows from the matrix to the fracture as a linear pattern too. The log-log plot of pressure and pressure derivative are two parallel lines. This period lasts a long time, and it is the main feature of the model. The pressure profile and flow pattern are shown in Fig. 6(c).

5. Pseudoradial flow of the system period: After the bilinear flow period, the flow effect extends to the matrix far away from the wellbore. Compared to the large area of the matrix, the fractures and wellbore are like a point. The fluid flows to this point from the horizontal direction as a radial pattern, which is shown in Fig. 6(d). The pressure derivative is a horizontal line, and the vertical value of this line represents the permeability of the matrix (Bourdet, 2002).

6. Boundary-dominated flow period: When the flow extends to the boundary, it changes to quasi-steady-state flow. Both the pressure and pressure derivative curves display a unit-slop line.

In the fractures case, we can conclude that the main feature of the fractures is the bilinear flow of the log-log plot. The expansion speed of pressure in the fractures is very fast due to the high permeability. Expansion of pressure shows obvious directivity along with the fractures.

\subsubsection{Effect of the Fracture Permeability}

Figure 7 shows the log-log plot of bottom hole pressure for different values of fracture permeability, $K_{f}$, namely $10^{4} \mathrm{mD}, 10^{5} \mathrm{mD}$, and $10^{6} \mathrm{mD}$. As can be seen, the fracture permeability mainly affects the radial flow period of the fractures. The larger $K_{f}$, the earlier the radial flow begins and the lower the horizontal line, which means the level of this horizontal line represents the permeability of the fractures. In the pseudoradial flow of the system period, the pressure derivative curves coincide because of the same permeability of the matrix. Another effect of the fracture permeability is in the bilinear flow period. The larger the $K_{f}$, the longer the bilinear flow period of the fractures and the larger the slope of the parallel lines in the bilinear flow. This is because larger $K_{f}$ means the linear flow in the fractures is faster than the linear flow from the matrix to the fractures and it tends to be a linear flow in the fracture.

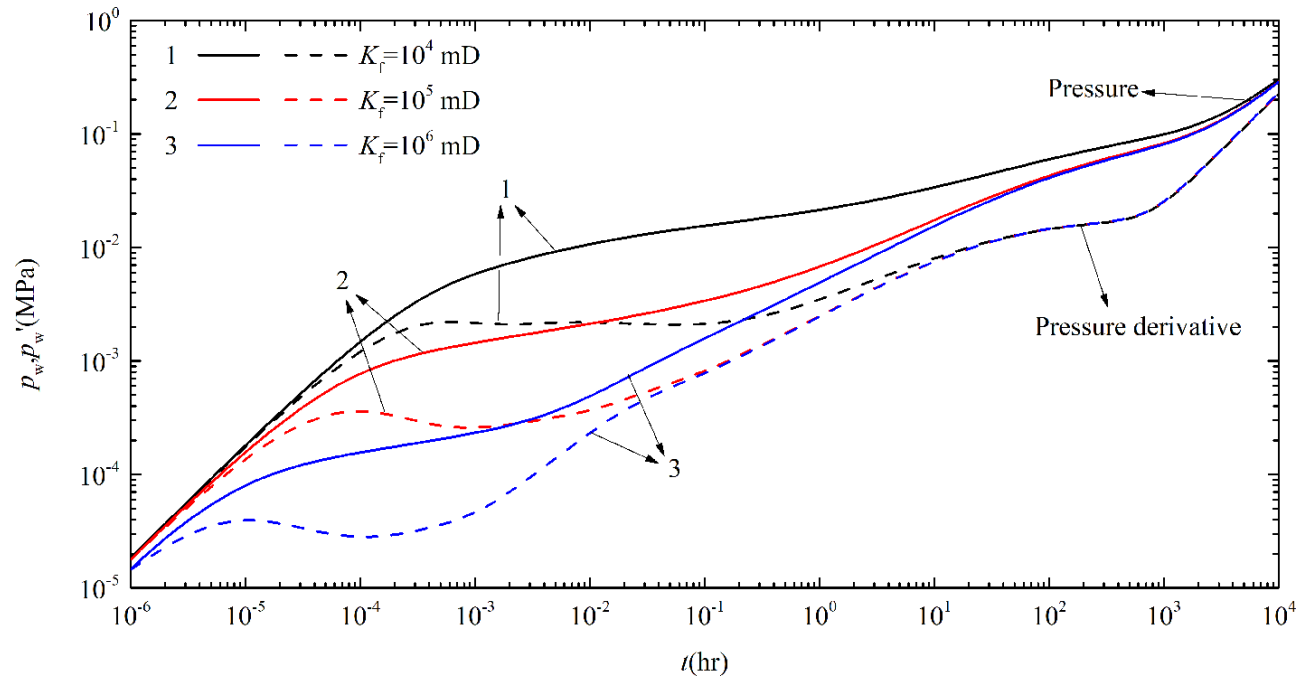

FIG. 7: Log-log plot of bottom hole pressure for different fracture permeability

Volume 22, Issue 11, 2019 


\subsection{The Case of Cavities}

The second case is one with cavities. Figure 8 shows a reservoir of $1,000 \times 1,000 \times 300 \mathrm{~m}$ with three cavities. The well is located in the biggest cavity, but not run through it. The permeability of the matrix is $1 \mathrm{mD}$. and that of the cavities is $10^{4} \mathrm{mD}$. In the development of fractured-caved reservoirs, the well is often designed to shoot the cavity because of the high permeability and large storage space of the cavity. Therefore, this model is very common in the fractured-caved reservoirs.

\subsubsection{Pressure Transient Analysis}

Figure 9 shows the log-log plot of the bottom hole pressure and pressure derivative changing with time. As can be seen, the type curves of the model can be divided into six stages.

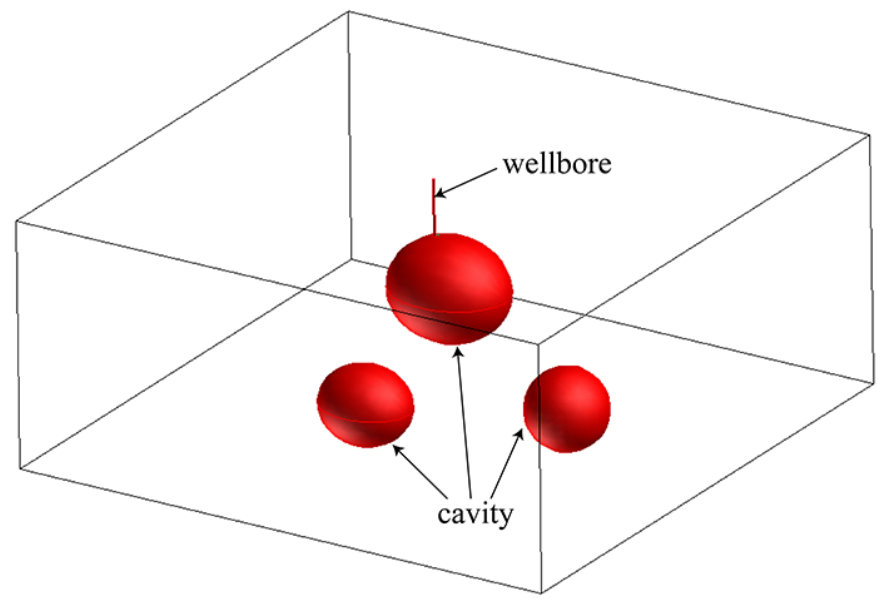

FIG. 8: Model of the cavity case

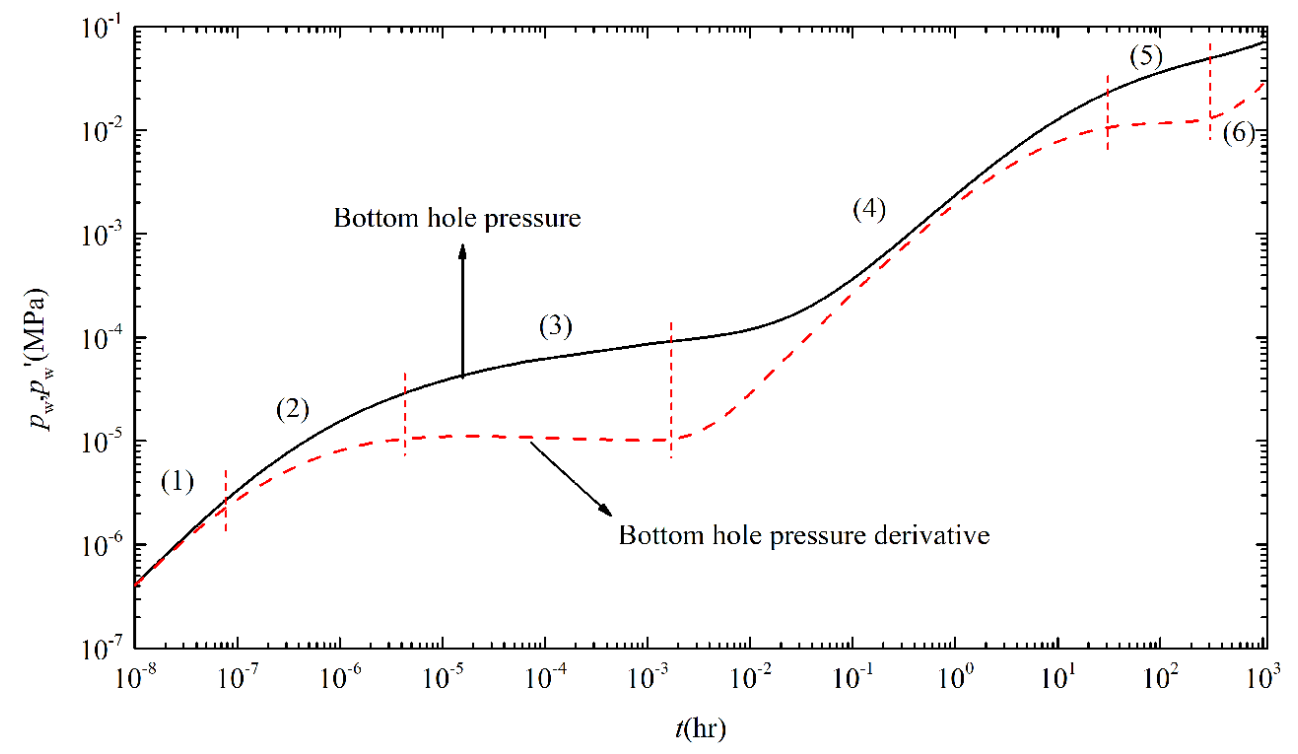

FIG. 9: Log-log plot of the bottom hole pressure 
1. Wellbore storage period: The pressure and derivative curve are straight lines with a unit slope.

2. Transient flow period: After the wellbore storage stage, the fluid starts to flow from the cavity to the wellbore.

3. Pseudoradial flow period of the cavity connected with the well: The pressure derivative is a horizontal line, and the vertical coordinate value represents the permeability of the cavity. Figure 10(a) shows the pressure profile of the slice that crosses the cavity in this period. The pressure in the cavity drops very fast because of the high permeability.

4. Transient flow period: With the pressure in the cavity drop, fluid in the matrix starts to flow into the cavity in which the well is located. The pressure and pressure derivative shift up from the horizontal line of the radial flow of the cavity in Period (3) and lasts for a long time because of the low permeability of the matrix. Figures 10(b) and 10(c) show the pressure profile of this period.

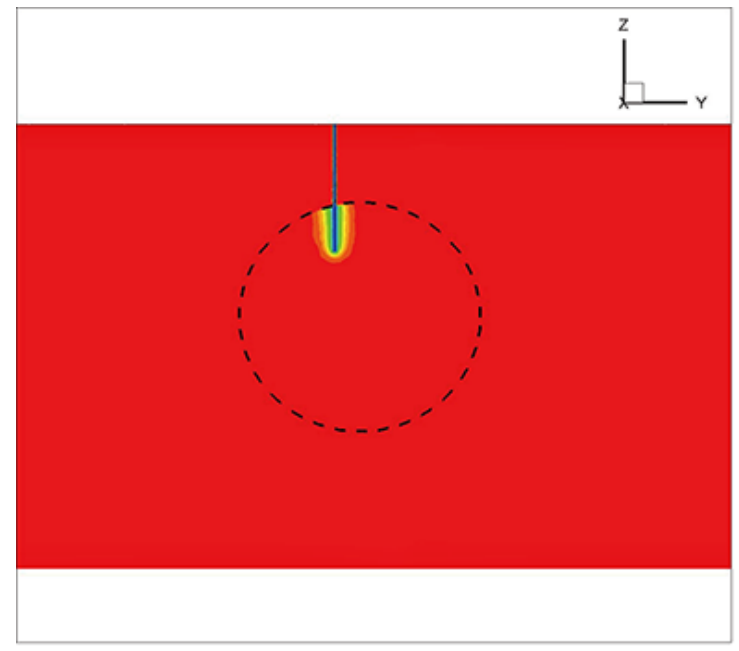

(a) Radial flow of the cavity ( $t=0.001 \mathrm{hr}$ )

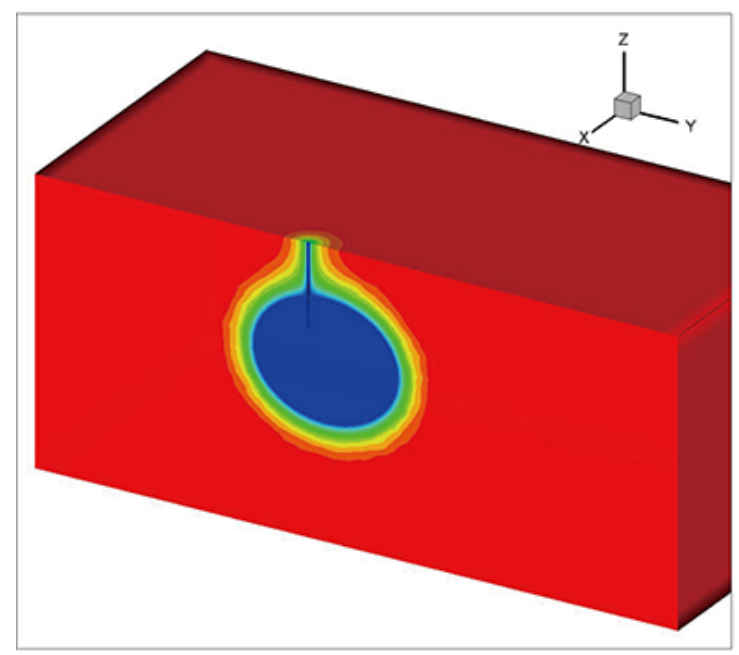

(c) Transient flow $(t=10 \mathrm{hr})$

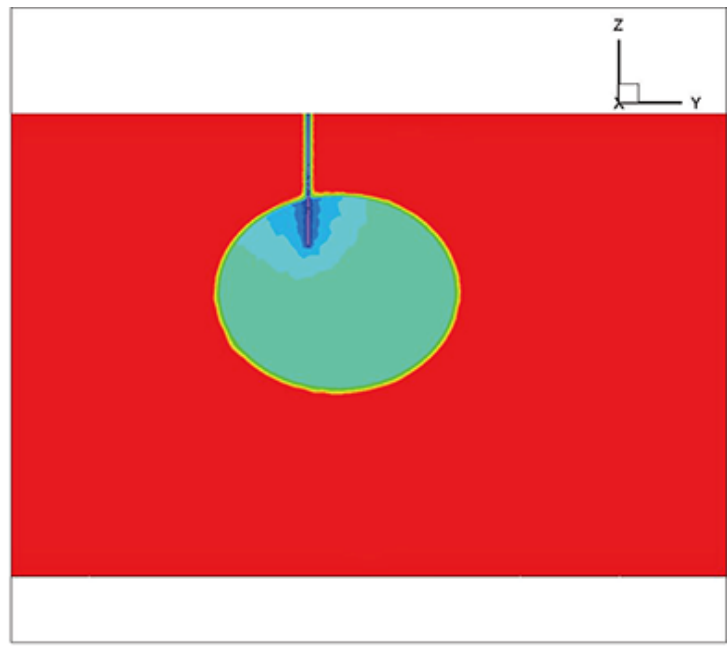

(b) Transient flow $(t=0.1 \mathrm{hr})$

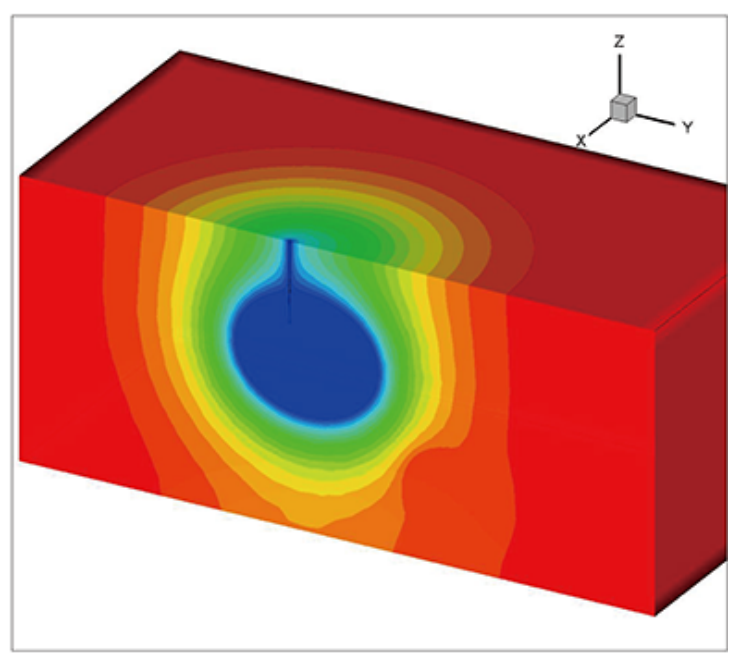

(d) Radial flow of the system $(t=100 \mathrm{hr})$

FIG. 10: Pressure field of the case of cavities: (a) radial flow of the cavity $(t=0.001 \mathrm{~h}$ ); (b) transient flow ( $t=0.1 \mathrm{~h})$; (c) transient flow $(t=10 \mathrm{~h})$; and $(\mathrm{d})$ radial flow of the system $(t=100 \mathrm{~h})$ 
5. Pseudoradial flow period of the system: After the transient flow, the fluid in the matrix far away from the wellbore starts to flow as a pseudoradial pattern. The pressure derivative is a horizontal line, and the vertical coordinate value of this line represents the permeability of the matrix. Figure 10(d) is the pressure profile. As can be seen, the pressure gradients of the other two cavities, which are away from the well, are small because of the high permeability.

6. Boundary dominated flow period: The pressure and pressure derivative display a line with a unit slope.

In the cavities case, we can see that the log-log plot is very similar to that of the fractures except for the bilinear flow period. In the process of the model evaluation in well tests, it is hard to decide the well test model based on the tested data. Another conclusion that we can make is that the cavity in which the well is located dominates the fluid flow of the system.

\subsubsection{Effect of the Cavities' Permeability}

Figure 11 shows the log-log plot of the bottom hole pressure for different cavities' permeability, namely $10^{3} \mathrm{mD}$, $10^{4} \mathrm{mD}$, and $10^{5} \mathrm{mD}$. As can be seen, the cavities' permeability, $K_{v}$, mainly affects the pseudoradial flow period of the cavity connected with the well. The larger the $K_{v}$, the lower the horizontal line of the pressure derivative and the earlier the radial flow starts. The cavities' permeability does not affect the radial flow of the system even though there are two cavities with high permeability in the matrix. This means the influence of cavities not connected with the wellbore on the fluid flow is very limited; in other words, the cavities not connected with the wellbore cannot be recognized by well testing.

\subsubsection{Comparison with the Radial-Composite Model}

From Figs. 9 and 11, we can see that the log-log plot of the cavity case is very similar to that of the radial-composite model. This is why lots of engineers use radial-composite models for well test interpretation. Thus, we make a comparison between the developed model with the radial-composite model to examine the differences. We use the geological model shown in Fig. 8 to compare with the radial-composite model. We assume the results of the cavity case are akin to field data and use the radial-composite model to implement a well test interpretation to fit the $\log$-log plot of the cavity case in Fig. 9. Table 2 shows the properties of the cavity case. Figure 12 shows the fitting plot of the two models.

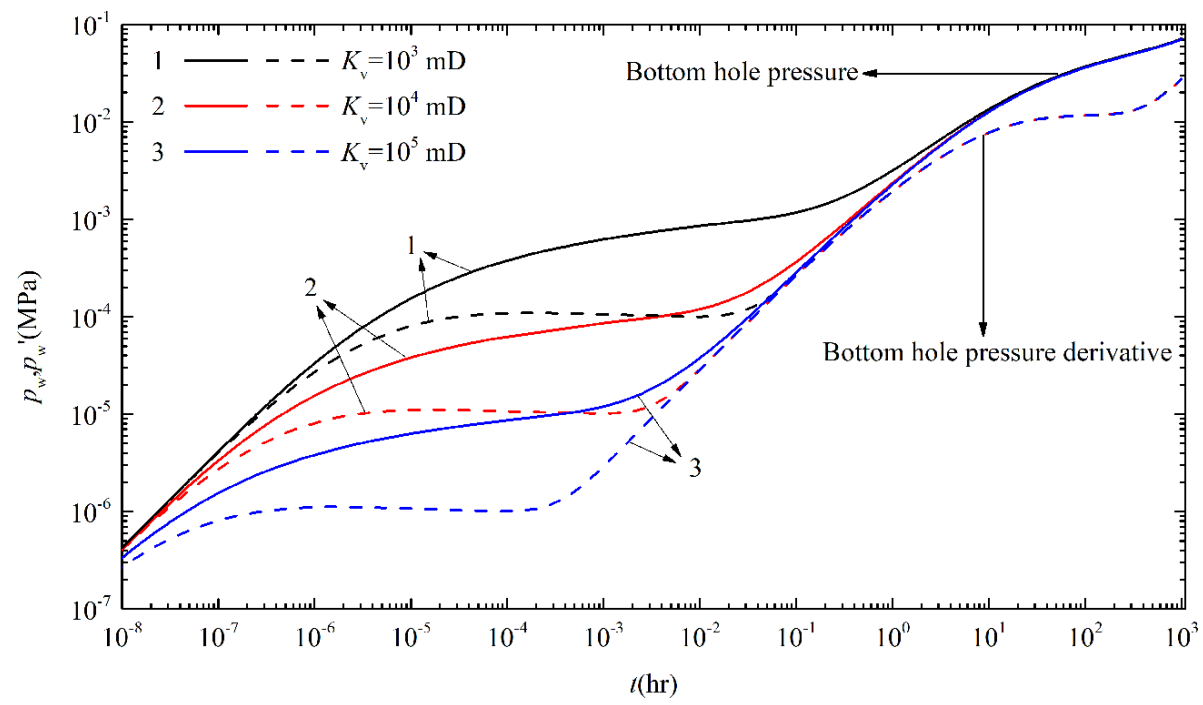

FIG. 11: Log-log plot of bottom hole pressure for different cavities' permeability 
TABLE 2: Reservoir and fluid properties of the assumed cavity case example

\begin{tabular}{|c|c|}
\hline Variable & Radial-composite model \\
\hline$p_{i}$ & $50 \mathrm{MPa}$ \\
\hline$h$ & $350 \mathrm{~m}$ \\
\hline$\mu$ & $1 \mathrm{mPa} \cdot \mathrm{s}$ \\
\hline$B$ & 1 \\
\hline$C_{t}$ & $0.0035 \mathrm{MPa}^{-1}$ \\
\hline$K_{v}$ & $10,000 \mathrm{mD}$ \\
\hline$K_{m}$ & $1 \mathrm{mD}$ \\
\hline$V_{v 1}{ }^{\dagger}$ & $1.91 \times 10^{6} \mathrm{~m}^{3}$ \\
\hline
\end{tabular}

${ }^{\dagger} V_{v 1}$ is the volume of the cavity in which the wellbore is located.

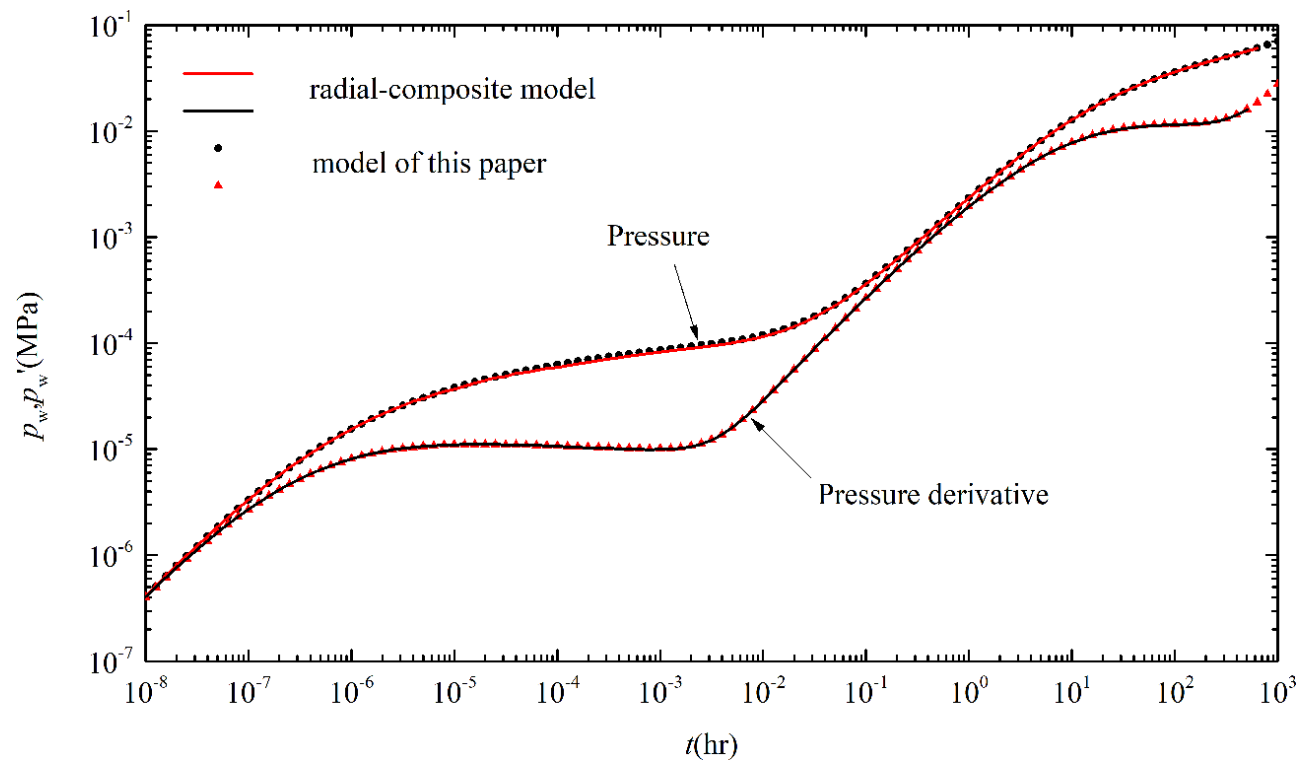

FIG. 12: Log-log fitting plot of the cavity case with radial-composite model (denoted as measured)

From Fig. 12, we can see that the log-log curves of the cavity case fit very well with that of the radial-composite model. Table 3 displays the parameters of the cavity case and the corresponding results of the radial-composite model from the fitting plot of the type curves. The wellbore storage coefficient interpreted by the radial-composite model is the same as the assumed value of the cavity case. We assume a zero skin in the cavity case, but the radial-composite model obtains a negative skin factor. We view the cavity in which the well is located as the inner zone of the radialcomposite model and the other regions as the outer zone. However, it should be noticed that the geological model of the cavity case is very different from that of the radial-composite model. First, in the cavity case of this paper, the cavity is an ellipsoid, which is not like the radial-composite model for which the inner zone runs through the entire reservoir in the vertical direction (Fig. 2). Second, the well in the cavity case is limited entry.

From the results of Table 3, we can see that the permeability of the outer zone in the radial-composite model is very close to the permeability of the matrix in the cavity case. The permeability of the inner zone of the radialcomposite model is $11,667 \mathrm{mD}$, which is $16.67 \%$ larger than the cavity permeability of the cavity case. As for the size of the cavity, we can only compare the volume of the radial-composite model and the cavity case because of the 
TABLE 3: Well test results of the assumed cavity case example using radial-composite model

\begin{tabular}{|c|c|c|}
\hline Variable & Radial-composite model & Cavity case (model in this paper) \\
\hline$C$ & $0.00117 \mathrm{~m}^{3} / \mathrm{MPa}$ & $0.001 \mathrm{~m}^{3} / \mathrm{MPa}$ \\
\hline$S$ & -1.1 & 0 \\
\hline$K_{m}{ }^{\ddagger}$ & $1.11 \mathrm{mD}$ & $1.00 \mathrm{mD}$ \\
\hline$K_{v}{ }^{\S}$ & $11,667 \mathrm{mD}$ & $10,000 \mathrm{mD}$ \\
\hline$r_{v}\left(\text { or } r_{i}\right)^{\mathbb{T}}$ & $41.92 \mathrm{~m}$ & $76.98 \mathrm{~m}$ \\
\hline
\end{tabular}

${ }^{\ddagger} K_{v}$ represents the permeability of the inner zone in the radial-composite model

${ }^{\S} K_{m}$ represents the permeability of the outer zone in the radial-composite model

${ }^{\mathbb{I}} r_{v}$ is the radius of the sphere of the cavity in which the well is located. In this case, the cavity is an ellipsoid, so $r_{v}$ is an equivalent sphere radius calculated with the principle of the volume equivalence. $r_{i}$ is the radius of the inner zone in the radial-composite model.

different geological definitions. The volume of the inner zone in the radial-composite model can be calculated by the following:

$$
V_{i}=\pi r_{i}^{2} h
$$

Substituting $r_{i}=41.92 \mathrm{~m}$ and $h=350 \mathrm{~m}$ into Eq. (22), we can get the volume of the inner zone is $1.93 \times$ $10^{6} \mathrm{~m}^{3}$, and it is very close to the actual volume $\left(1.91 \times 10^{6} \mathrm{~m}^{3}\right)$ of the cavity in Table 1 . From this comparison, we can conclude that, in the well test interpretation of the cavity case, the radial-composite model can give a volume equivalent radius of the cavity, but a higher permeability and a negative skin factor.

\subsection{The Case of Fractures and Cavities}

In this section, we will demonstrate an oil-field case whose fractures and cavities are modeled based on seismic characterization. A numerical well testing interpretation will be implemented based on this model, and the parameters of the cavities and fractures will be obtained. This example is presented to show the application of the model developed in this paper.

Figure 13(a) shows the seismic reflection profile around a well named Well A. It shows a typical bead-reflection, which implies fractures and cavities of large scale. Figure 13(b) shows the plane projection of the fractured-caved unit for Well A, which is drawn according to the seismic data. From Fig. 13(b), we can see that there are four cavities in this fractured-caved unit. The wellbore is not located in any cavities, but two fractures connected two cavities with the wellbore.

Based on the seismic data presented in Figs. 13(a) and 13(b), topological information of the fractures, cavities, and reservoirs are acquired, and the geological model is developed as shown in Fig. 13(c). The shape of cavities in this model is irregular, and two of them are connected with wellbore directly by fractures.

The log-log type curves of Well A are presented in Fig. 14. The denoted lines in Fig. 14 are the tested bottom hole pressure of a well test. They are obtained using a high-precision gauge at the bottom of the wellbore (Gringarten, 2012). Other parameters are as follows: the radius of the wellbore is $0.0746 \mathrm{~m}$, the surface flow rate is $140 \mathrm{~m}^{3} / \mathrm{d}$, the thickness of the reservoir is $141 \mathrm{~m}$, the matrix permeability is $1.29 \%$, the volume factor of oil is $1.037 \mathrm{~m}^{3} / \mathrm{m}^{3}$, the viscosity is $2.19 \mathrm{mPa} \cdot \mathrm{s}$, and the total compressibility is $1.42 \times 10^{-3} \mathrm{MPa}^{-1}$.

We use the model developed in this paper to compute the bottom hole pressure of the well and to fit the test data by adjusting the parameters of cavities and fractures. The fitting plot is shown in Fig. 14, and the fitting parameters are listed in Table 4. From Table 4, we can conclude that the permeability of fractures is extremely high, which implies a good connection between the well and the cavities, and the permeability of the cavities is also large. This is why the production rate of Well $\mathrm{A}$ is large.

Figure 15 shows the pressure field of a horizontal slice. From the figure, we can see that the pressure firstly expands along the fractures directly connected with the wellbore. Then, the pressure wave propagates rapidly to the 

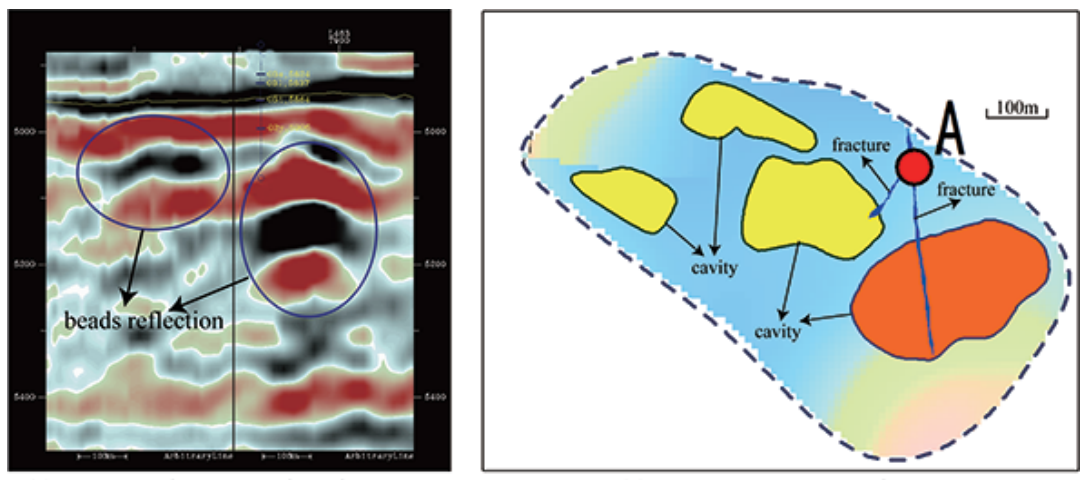

(a) Seismic reflection profile of well-A

(b)Fractured-caved unit of the well-A

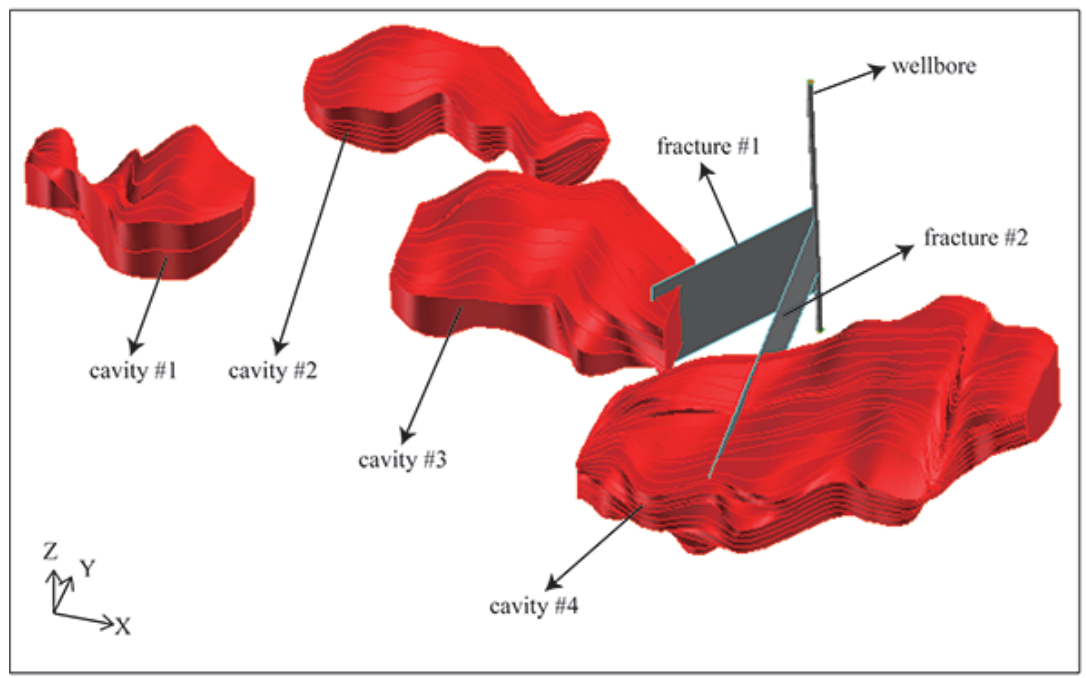

(c) 3D geological model for the simulation of well-A

FIG. 13: Geological modelling of Well A: (a) seismic reflection profile; (b) fractured-caved unit; and (c) 3D geological model for simulation

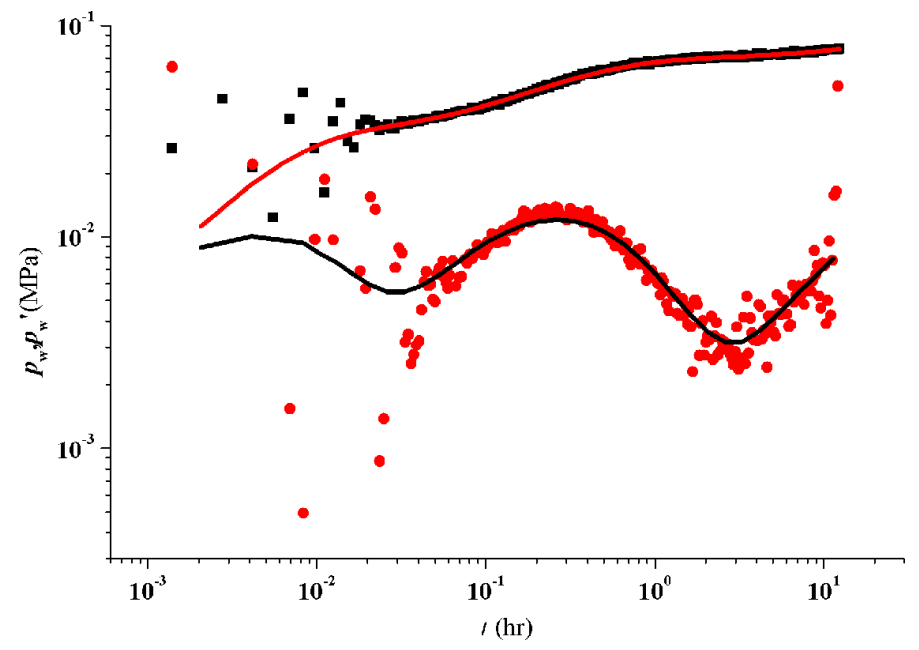

FIG. 14: Fit of the field data with log-log type curve of bottom hole pressure 
TABLE 4: Parameters interpreted from the well testing

\begin{tabular}{|c|c|c|}
\hline Parameters & Value & Unit \\
\hline Permeability of Fracture 1 & 10050 & $\mathrm{mD}$ \\
\hline Permeability of Fracture 2 & 12010 & $\mathrm{mD}$ \\
\hline Permeability of Cavity 1 & 650 & $\mathrm{mD}$ \\
\hline Permeability of Cavity 2 & 520 & $\mathrm{mD}$ \\
\hline Permeability of Cavity 3 & 2031 & $\mathrm{mD}$ \\
\hline Permeability of Cavity 4 & 1050 & $\mathrm{mD}$ \\
\hline Permeability of matrix & 1.02 & $\mathrm{mD}$ \\
\hline Wellbore storage & 0.071 & $\mathrm{~m}^{3} / \mathrm{MPa}$ \\
\hline
\end{tabular}

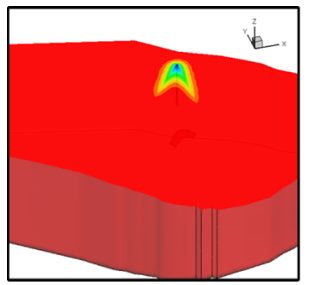

(a) $\mathrm{t}=0.1 \mathrm{hr}$

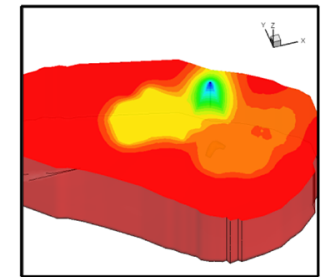

(b) $\mathrm{t}=10 \mathrm{hr}$

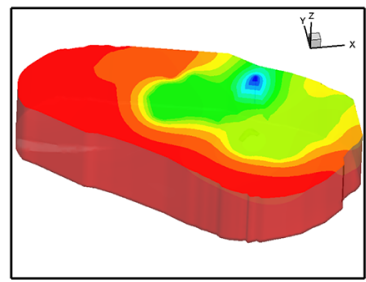

(c) $\mathrm{t}=100 \mathrm{hr}$

p(MPa): $55.00 \quad 56.27 \quad 57.55 \quad 58.82 \quad 60.09 \quad 61.36 \quad 62.00$

FIG. 15: Pressure filed of the horizontal slice: (a) $t=0.1 \mathrm{~h}$; (b) $t=10 \mathrm{~h}$; and (c) $t=100 \mathrm{~h}$

cavities connected with the fractures because of the high permeability. After that, the pressure decreases in the whole cavity. Figure 15 shows a typical flow manner of the fractured-caved reservoir, i.e., cavities are the main volume for fluid storage and fractures provide the flow path. In this field case, although the well is not located in any cavities, the fractures connect Cavity 3 and Cavity 4 with the wellbore. Therefore, Cavity 3 and Cavity 4 play important roles in the fluid flow.

All results analyzed in this paper indicate that the 3D transient pressure analysis model is applicable for modeling fluid flow in the fractured-caved reservoirs in a simple but valid enough way. This model can be used in the field case of well test interpretation to evaluate the reservoir.

\section{LIMITATIONS OF THE PROPOSED MODEL}

The model developed in this paper has some limitations because of the simplification: (1) It only takes account of the filled cavities in which the fluid flow obeys Darcy's law; therefore, it cannot model the fluid flow in the unfilled cavities. (2) The model is only applicable for modeling fluid flow in a single-phase oil flow. (3) The permeability of the matrix, fractures, and cavities is isotropic. (4) The properties of the reservoir and fluid are constant.

\section{CONCLUSIONS}

In this paper, a geological modeling process based on 3D seismic characterization is proposed to model real reservoirs, and then a 3D pressure transient analysis model is developed to model the fluid flow in the fractured-caved reservoirs.

The log-log type curves of bottom hole pressure of the fracture case can be divided into six stages. Bilinear flow is the main feature, and larger permeability of fractures causes an earlier beginning for the radial flow and a lower 
horizontal line of the pressure derivative. The larger permeability of fractures causes a longer bilinear flow period of the fractures and a larger slope of the parallel lines in the bilinear flow.

Log-log type curves of cavities show six periods. The pseudoradial flow of the cavity is the main feature, and larger permeability of cavities causes a lower horizontal line of the pressure derivative. The cavity that the well is located in dominates the fluid flow, but the influence of cavities not connected with wellbore is very limited, which means the cavities not connected with the wellbore cannot be recognized by well testing.

The comparison between cavity case and the radial-composite model shows that the radial-composite model can get the right permeability of the matrix, but a volume equivalent radius of the cavity, a higher permeability and a negative skin factor. In the well test interpretation of fractured-caved reservoirs, the radial-composite model is not accurate.

A field model is developed, and we apply the model proposed in this paper in the well testing interpretation of the field case. The pressure field shows that the cavities are important for the production because they are the main storage volume of fluid, and the fractures are also important as the connection of wells and cavities, or cavities and cavities.

\section{ACKNOWLEDGMENTS}

This work was supported by Shandong Provincial Natural Science Foundation (No. ZR2019BD058), the Laboratory for Marine Mineral Resources, Qingdao National Laboratory for Marine Science and Technology (No. MMRZZ201807), the National Key R\&D Program of China (2018YFC0309204), and the Marine Geological Survey Program (No. DD20190231).

\section{REFERENCES}

Barenblatt, G.I., Zheltov, I.P., and Kochina, I.N., Basic Concepts in the Theory of Seepage of Homogeneous Liquids in Fissured Rocks [Strata], J. Appl. Math. Mech, vol. 24, pp. 1286-1303, 1960.

Bourdet, D., Well Test Analysis: The Use of Advanced Interpretation Models, First Ed., Amsterdam, Netherlands: Elsevier, 2002.

Clossman, P.J., An Acquirer Model for Fissured Reservoir, SPE J., vol. 15, pp. 385-398, 1975.

Dayani, S., Baghbanan, A., and Karami, M., Evaluating the Permeability Tensor of a Fractured Rock Mass Using Effective Medium Theory, Proc., Rock Engineering and Technology for Sustainable Underground Construction, the 2012 ISRM Int. Symp., Stockholm, Sweden, May 28-30, 2012.

de Swaan, O.A., Analytic Solutions for Determining Naturally Fractured Reservoir Properties by Well Testing, SPE J., vol. 16, pp. $117-122,1976$.

Fuentes-Cruz, G. and Valko, P.P., Revisiting the Dual-Porosity/Dual-Permeability Modeling of Unconventional Reservoirs: The Induced-Interporosity Flow Field, SPE J., vol. 20, pp. 124-141, 2015.

Galerkin, B.G., Rods and Plates: Series in Some Problems of Elastic Equilibrium of Rods and Plates, Vestn. Inzh. Tech., (USSR), vol. 19, pp. 897-908, 1915.

Grillo, A., Lampe, M., Logashenko, D., Stichel, S., and Wittum, G., Simulation of Salinity and Thermohaline-Driven Flow in Fractured Porous Media, J. Porous Media, vol. 15, no. 5, pp. 439-458, 2012

Gringarten, A.C., Well Test Analysis in Practice, The Way Ahead, vol. 8, pp. 10-14, 2012.

Huang, Z.Q., Xia, Y., and Yao, J., A Two-Phase Flow Simulation of Discrete-Fractured Media Using Mimetic Finite Difference Method, Commun. Comput. Phys., vol. 16, pp. 799-816, 2014.

Huang, Z.Q., Yao, J., Li, Y.J., Wang, C.C., and Lu, X.R., Permeability Analysis of Fractured Vuggy Porous Media based on Homogenization Theory, Sci. China: Tech. Sci., vol. 53, pp. 839-847, 2010.

Jambayev, A.S. and Hoffman, B.T., Predicting Water Movement Using a Discrete Fracture Network Approach Combined with Fluid Flow Modeling in a Naturally Fractured Carbonate Reservoir, SPE-172785-MS, SPE Middle East Oil \& Gas Show and Conf., Manama, Bahrain, March 8-11, 2015.

Kazemi, H., Pressure Transient Analysis of Naturally Fractured Reservoirs with Uniform Fracture Distribution, SPE J., vol. 9, pp. 451-462, 1969.

Volume 22, Issue 11, 2019 
Khvatova, I.E., Renaud, A., Golitsina, E., Malutina, G., Sansiev, G., and Kuzilov, I., Simulation of Complex Carbonate Field: Double Media vs. Single Media Kharyaga Field Case (Russian), SPE Russian Oil and Gas Exploration and Production Technical Conf. and Exhibition, Moscow, Russia, October 16-18, 2012.

Kim, J.G. and Deo, M.D., Comparison of the Performance of a Discrete Fracture Multiphase Model with Those Using Conventional Methods, SPE Reservoir Simulation Symposium, Houston, Texas, February 14-17, 1999.

Kolditz, D.I.O., Non-Linear Flow in Fractured Media, Berlin: Springer, 2002.

Li, Y., Zhang, J., Liu, Z.L., and Li, B., A Systematic Technique of Production Forecast for Fractured Vuggy Carbonate Gas Condensate Reservoirs, The SPE Kingdom of Saudi Arabia Technical Symposium and Exhibition, Dammam, Saudi Arabia, April 25-28, 2016.

Long, J.C.S., Remer, J.S., and Wilson, C.R., Porous Media Equivalents for Networks of Discontinuous Factures, Water Resour. Res., vol. 18, pp. 645-658, 1982.

Loucks, T.L. and Guerrero, E.T., Pressure Drop in a Composite Reservoir, SPE J., vol. 1, pp. 170-176, 1961.

Ran, Q., Wang, Y., Sun, Y., Yan, L., and Tong, M., Volcanic Gas Reservoir Characterization, First Ed., Boston: Gulf Professional Publishing, 2014.

Shakerinezhad, S., Samadi, F., and Esmaielzadeh, F., Pressure Transient Response of Partially Fractured Reservoirs, Spcl. Top. Rev. Porous Media - Int. J., vol. 4, no. 1, pp. 1-11, 2013.

Snow, D.T., Anisotropic Permeability of Fractured Media, Water Resour. Res., vol. 5, pp. 1273-1289, 1969.

Teimoori, A., Calculation of the Effective Permeability and Simulation of Fluid Flow in Naturally Fractured Reservoirs, PhD, University of New South Wales, Sydney, Australia, 2005.

Wan, Y.Z. and Liu, Y.W., Three Dimensional Discrete-Fracture-Cavity Numerical Well Test Model for Fractured-Cavity Reservoir, Chin. J. Theor. Appl. Mech., vol. 47, pp. 1000-1008, 2015.

Wan, Y.Z., Liu, Y.W., Chen, F.F., Wu, N.Y., and Hu, G.W., Numerical Well Test Model for Caved Carbonate Reservoirs and Its Application in Tarim Basin, China, J. Pet. Sci. Eng., vol. 161, pp. 611-624, 2018.

Wan, Y.Z., Liu, Y.W., Ouyang, W.P., Han, G.F., and Liu, W.C., Numerical Investigation of Dual-Porosity Model with Transient Transfer Function based on Discrete-Fracture Model, Appl. Math. Mech., vol. 37, pp. 611-626, 2016.

Warren, J.E. and Root, P.J., The Behavior of Naturally Fractured Reservoirs, SPE J., vol. 3, pp. 245-255, 1963.

Xing, C.Q., Yin, H.J., Liu, K.X., and Fu, J., Well Test Analysis for Fractured and Vuggy Carbonate Reservoirs of Well Drilling in Large Scale Cave, Energies, vol. 11, pp. 80-85, 2018.

Yao, J., Wang, C.C., Yang, Y.F., Huang, Z.Q., Fan, D.Y., and Sun, H., The Construction Method and Microscopic Flow Simulation of Carbonate Dual Pore Network Model, Sci. Sin-Phys: Mech. Astron., vol. 43, pp. 896-902, 2013.

Yao, S.S., Wang, X.Z., and Zeng, F.H., A Composite Model for Multi-Stage Fractured Horizontal Wells in Heterogeneous Reservoirs (Russian), The SPE Russian Petroleum Technology Conference and Exhibition, Moscow, Russia, October 24-26, 2016.

Yu, X., Rutledge, J., Leaney, S., and Maxwell, S., Discrete Fracture Network Generation from Microseismic Data Using MomentTensor Constrained Hough Transforms, SPE Hydraulic Fracturing Technology Conf., The Woodlands, Texas, February 4-6, 2014.

Zendehboudi, S., Chatzis, I., Shafiei, A., and Dusseault, M.B., Empirical Modeling of Gravity Drainage in Fractured Porous Media, Energy Fuels, vol. 25, pp. 1229-1241, 2011.

Zendehboudi, S., Elkamel, A., Chatzis, I., Ahmadi, M.A., Bahadori, A., and Lohi, A., Estimation of Breakthrough Time for Water Coning in Fractured Systems: Experimental Study and Connectionist Modeling, AIChE J., vol. 60, pp. 1905-1919, 2014.

Zendehboudi, S., Mohammadzadeh, O., and Chatzis, I., Experimental Study of Controlled Gravity Drainage in Fractured Porous Media, J. Canadian Petro. Tech., vol. 50, pp. 56-71, 2009.

Zhang, G.K., and Xu, W.Y., Analysis of Joint Network Simulation Method and REV Scale, Rock Soil Mech., vol. 29, pp. 16751680, 2008.

Zheng, D.M., Li, Z.H., Zhao, K.Z., Shen, F., Dang, Q.N., and Gao, L.H., Quantitative Seismic Characterization of Ordovician Fracture-Cavity Carbonate Reservoirs in Tarim Oilfield, China Petro. Explo., vol. Z1, pp. 57-62, 2011.

Zhu, G.Y., Zou, C.N., Yang, H.J., Wang, K., Zheng, D., and Zhu, Y., Hydrocarbon Accumulation Mechanisms and Industrial Exploration Depth of Large-Area Fracture-Cavity Carbonates in the Tarim Basin, Western China, J. Pet. Sci. Eng., vol. 133, pp. 889-907, 2015. 